\title{
High sensitivity sapphire FBG temperature sensors for the signal processing of data communications technology
}

\author{
Mahmoud M. A. Eid', Ashraf S. Seliem², Ahmed Nabih Zaki Rashed ${ }^{3}$, Abd El-Naser A. Mohammed ${ }^{4}$, \\ Mohamed Yassin Ali ${ }^{5}$, and Shaimaa S. Abaza ${ }^{6}$ \\ ${ }^{1}$ Department of Electrical Engineering, College of Engineering, Taif University, Kingdom of Saudi Arabia \\ ${ }^{3,4}$ Electronics and Electrical Communications Engineering Department, Menoufia University, Egypt \\ 2,5,6 Benha Faculty of Engineering, Benha University, Benha, Egypt
}

\begin{tabular}{|c|c|}
\hline Article Info & ABSTRACT \\
\hline Article history: & This study has outlined the fiber bragg grating (FBG) temperature sensors \\
\hline Received Jul 27, 2020 & signal processing for data communications by using OptiGrating simulation \\
\hline Revised Oct 17, 2020 & reported against the grating wavelength for internal and external temperature \\
\hline Accepted Nov 29, 2020 & $\begin{array}{l}\text { variations. As well as apodized Gaussian reflectivity of the silica and } \\
\text { Sapphire fiber grating spectrum is simulated and clarified against the grating }\end{array}$ \\
\hline Keywords: & $\begin{array}{l}\text { wavelength for high temperature variations. The temperature sensitivity of } \\
\text { sapphire FBG nearly } 0.11 \mathrm{pm} /{ }^{0} \mathrm{C} \text {, where its value is three times higher than }\end{array}$ \\
\hline $\begin{array}{l}\text { Data communications } \\
\text { FBG device } \\
\text { Signal processing }\end{array}$ & $\begin{array}{l}\text { silica FBG. It is observed that silica and Sapphire FBG sensors were tested } \\
\text { up to } 1000{ }^{\circ} \mathrm{C} \text { by using Gaussian apodization type, side lobes in reflectivity } \\
\text { spectrum are totally suppressed. }\end{array}$ \\
\hline
\end{tabular}

This is an open access article under the CC BY-SA license.

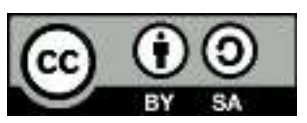

Corresponding Author:

Ahmed Nabih Zaki Rashed

Electronics and Electrical Communications Engineering Department

Menoufia University, Gamal Abd El-Nasir, Qism Shebeen El-Kom

Shibin el Kom, Menofia Governorate, Egypt

Email: ahmed_733@yahoo.com

\section{INTRODUCTION}

For a uniform FBG, the spectral response is affected by the length of grating which is changed by external perturbation such as strain, temperature and pressure [1-9]. Reflectivity based on designed model for a uniform FBG using OptiSystem simulator was analyzed at different values of grating length. Their results show the reflectivity of the uniform FBG increased as the grating length increased but reflectivity of side lobes also increased [7-12], and the bandwidth of a FBG reduced as increasing in grating length. Their results for the reflectivity of FBG, it was provide highly better performance as increasing in grating length and given $99.99 \%$ power reflection at $20 \mathrm{~mm}$ of grating length [4-7, 10-12, 13-15].

\section{MODEL DESCRIPTION}

FBG based sensor device used for the temperature, strain, pressure and flow measurement has been studied over the past several years [13-15]. Sapphire optical fiber provides a highly resistant against radiation and has a melting point up to $2000{ }^{\circ} \mathrm{C}$ [16-20]. It provides excellent temperature profile also at low temperatures given radiation resistant [16]. Sapphire FBG is used as a temperature sensors up to $1600{ }^{\circ} \mathrm{C}[18$ 29]. The Bragg wavelength with the grating period and effective fiber index is [7, 30-49]: 


$$
\lambda_{B}=2 n_{e f f} \Lambda
$$

Temperature and strain induced Bragg wavelength shifted shown as [15, 34-38]:

$$
\begin{aligned}
& \Delta \lambda_{B}=\lambda_{B}\left[\Delta T\left(\alpha+\frac{1}{n} \frac{d n}{d T}\right)+\varepsilon\left(1-\frac{n^{2}}{2}\left[p_{12}-v\left(p_{12}+p_{11}\right)\right]\right)\right] \\
& \Delta \lambda_{B}=\lambda_{B}\left[\Delta T\left(\alpha+\frac{1}{n_{\text {eff }}} \frac{d n}{d T}\right)\right] \\
& K_{T}=\lambda_{B}\left(\alpha+\frac{1}{n_{\text {eff }}} \frac{d n}{d T}\right)
\end{aligned}
$$

With $\Delta \mathrm{T}$ is the temperature variation, $\alpha$ is the temperature optic factor, $\varepsilon$ is the applied strain, $v$ is the poisons ratio and $\mathrm{p}_{11}, \mathrm{p}_{12}$ are the strain optic coefficients and $\mathrm{K}_{\mathrm{T}}$ is the coefficient for temperature sensitivity. Shift in Bragg wavelength $\lambda_{\mathrm{B} \mid \mathrm{T}}$ induced by temperature changes is described by [20-24]:

$$
\begin{aligned}
& \Delta \lambda_{B \mid T}=\lambda_{B}(\alpha+\xi) \Delta T \\
& \alpha=\frac{1}{\Lambda}\left(\frac{\partial \Lambda}{\partial T}\right) \\
& \xi=\frac{1}{n_{e f f}}\left(\frac{\partial n_{e f f}}{\partial T}\right)
\end{aligned}
$$

With $\Lambda$ is the period of the grating, $\alpha$ is the fiber thermal expansion, and $\xi$ is the thermo-optic factor [21].

\section{PERFORMANCE ANALYSIS WITH DISCUSSIONS}

As shown in Figure 1 and Figure 2 at the internal temperature of $37.1^{\circ} \mathrm{C}$, the Bragg wavelengths were $1.55018 \mu \mathrm{m}$ for FBG written in silica optical fiber and $1.55038 \mu \mathrm{m}$ for a Sapphire Bragg grating respectively. Also in Figure 3, Figure 4 at the outlet temperature from the reactor core $44{ }^{0} \mathrm{C}$ the Bragg wavelengths were $1.55025 \mu \mathrm{m}$ for FBG in silica optical fiber and $1.55059 \mu \mathrm{m}$ for a Sapphire fiber Bragg grating respectively.

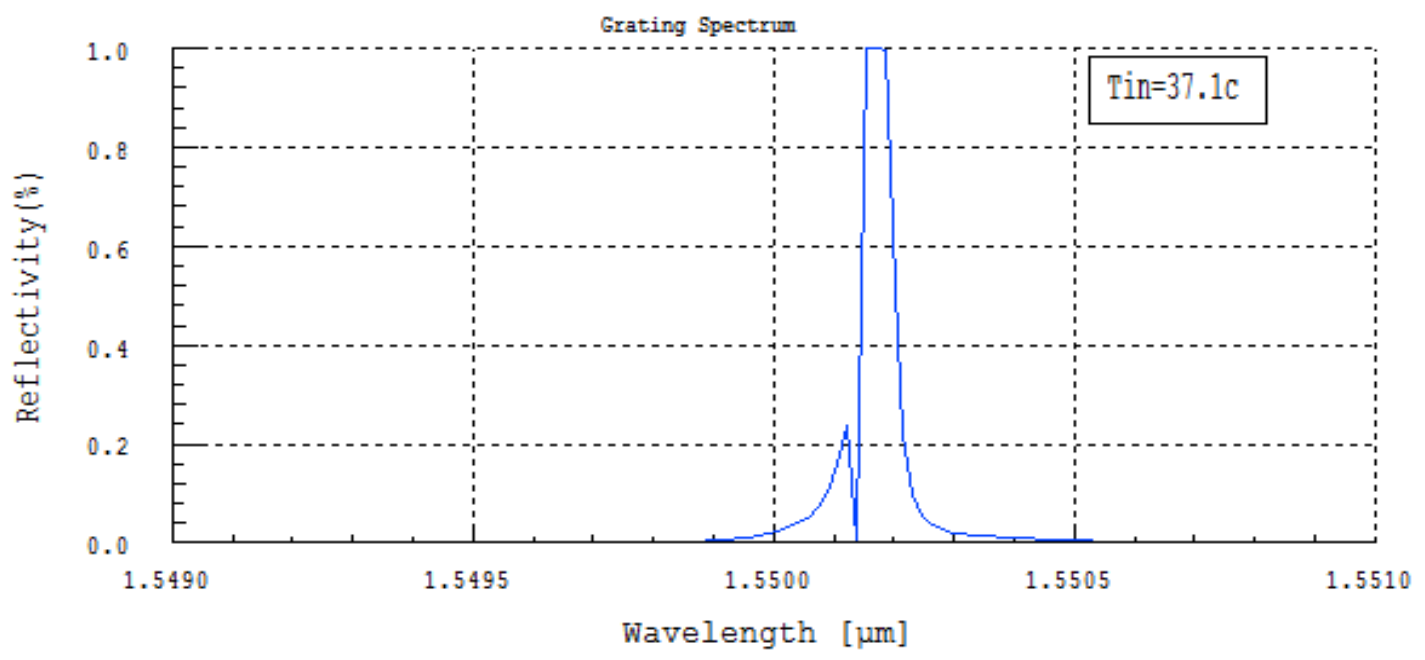

Figure 1. Reflectivity of the silica fiber grating spectrum versus the grating wavelength for internal temperature of 37.1 ${ }^{\circ} \mathrm{C}$. 


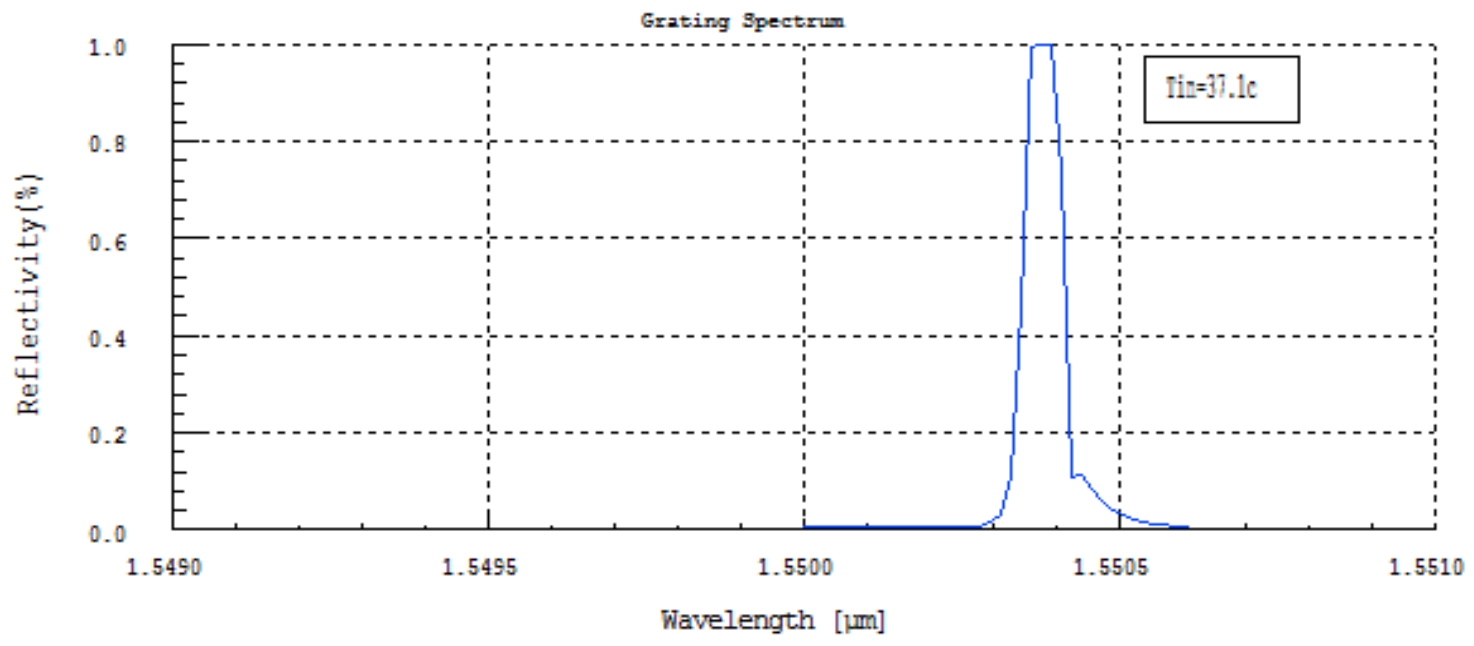

Figure 2. Reflectivity of the Sapphire fiber grating spectrum with grating wavelength for internal temperature of $37.1^{\circ} \mathrm{C}$.

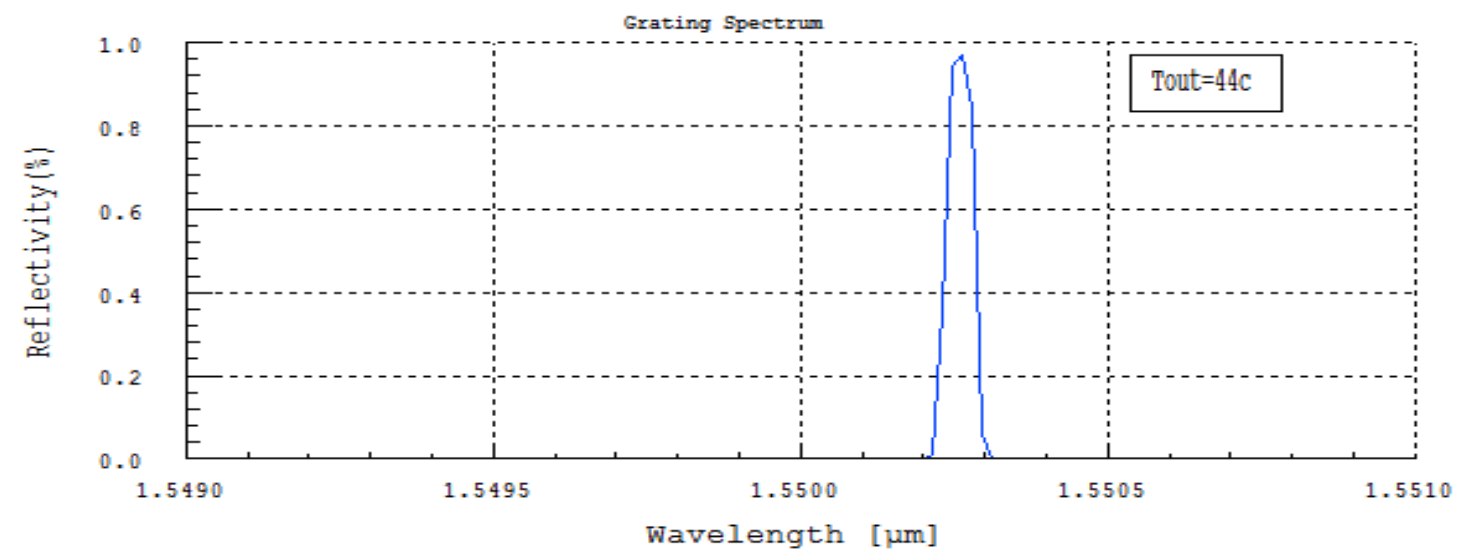

Figure 3. Reflectivity of the silica fiber grating spectrum versus the grating wavelength for external temperature of $44{ }^{\circ} \mathrm{C}$.

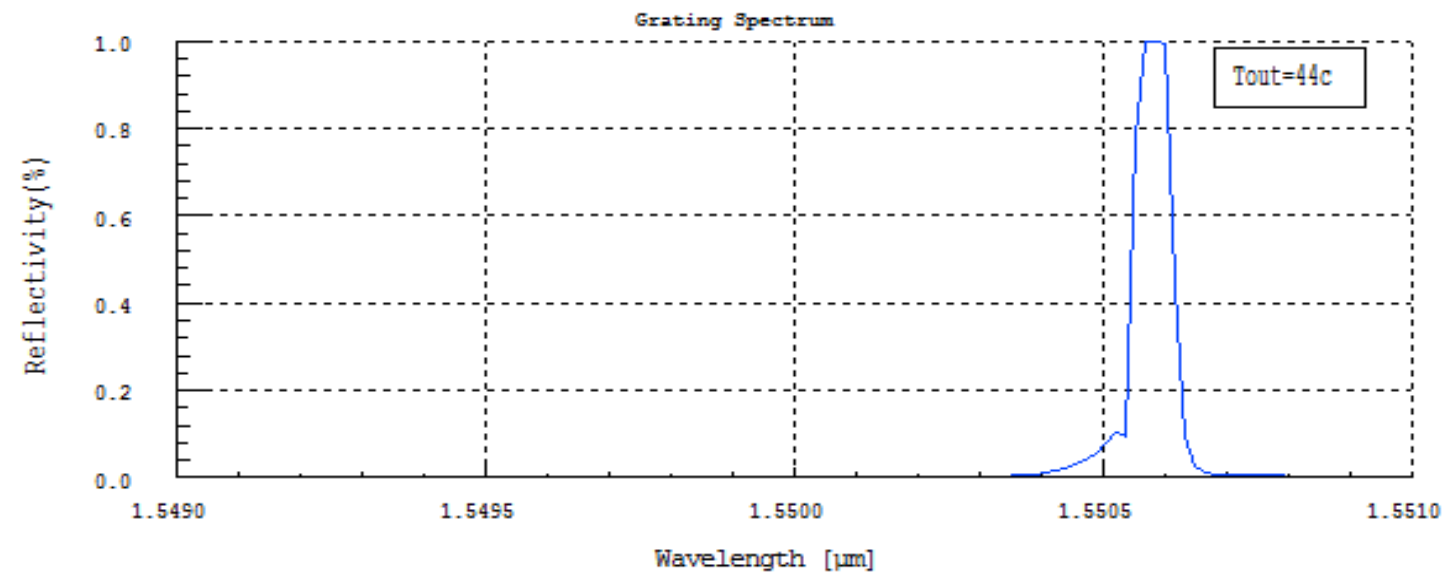

Figure 4. Reflectivity of the Sapphire fiber grating spectrum with grating wavelength for external temperature of $44{ }^{\circ} \mathrm{C}$.

From Figure 5- 6 and from Figure 7-8, the Bragg wavelength shift as a result of temperature changes for the inlet and outlet temperature for both FBG written in silica optical fiber and Sapphire Bragg grating respectively, all of side lobes have been completely eliminated whicfh provide an accurate temperature measurements that must be achieved in nuclear applications. 


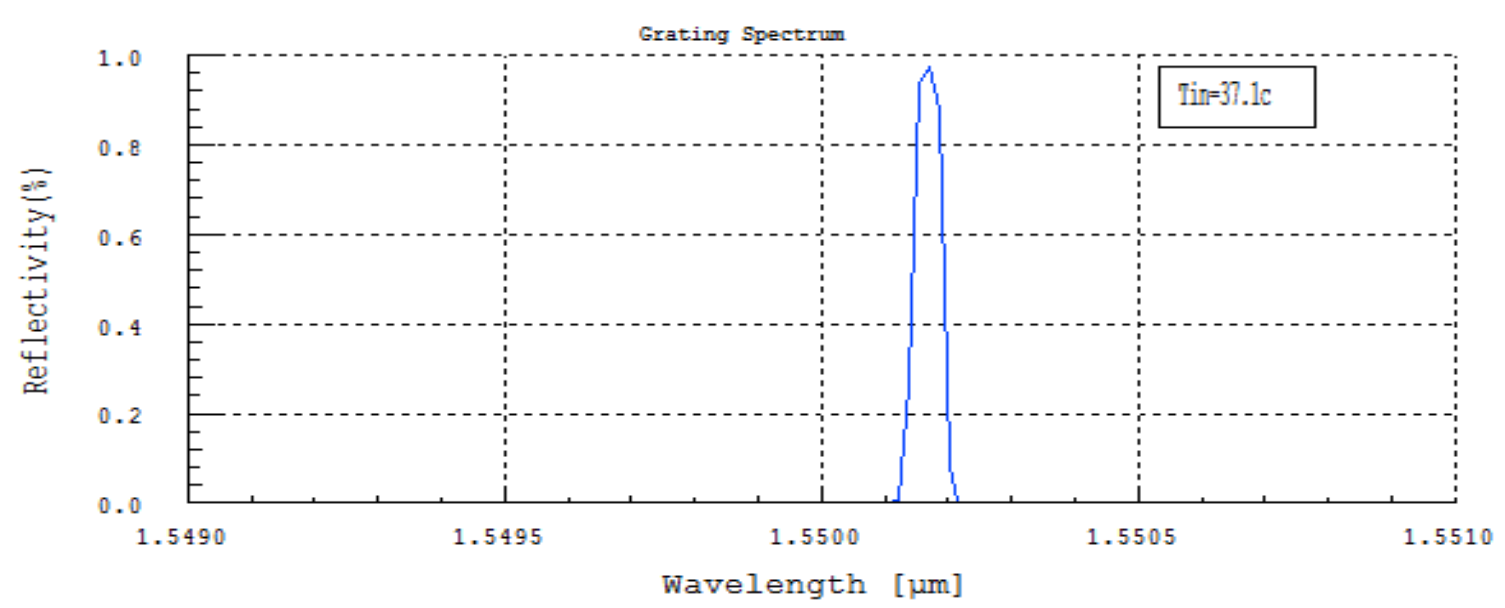

Figure 5. Apodized reflectivity of the silica fiber grating spectrum versus the grating wavelength for internal temperature of $37.1^{\circ} \mathrm{C}$

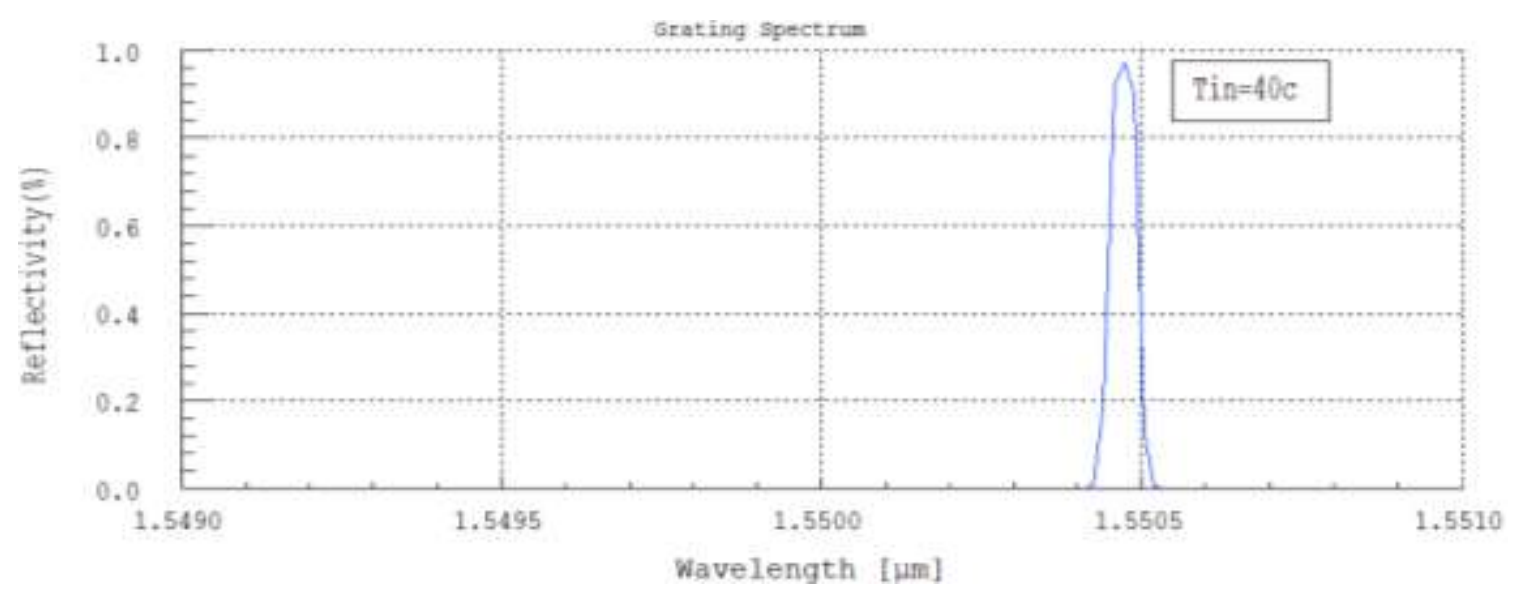

Figure 6. Apodized reflectivity of the Sapphire fiber grating spectrum versus the grating wavelength for internal temperature of $40{ }^{\circ} \mathrm{C}$

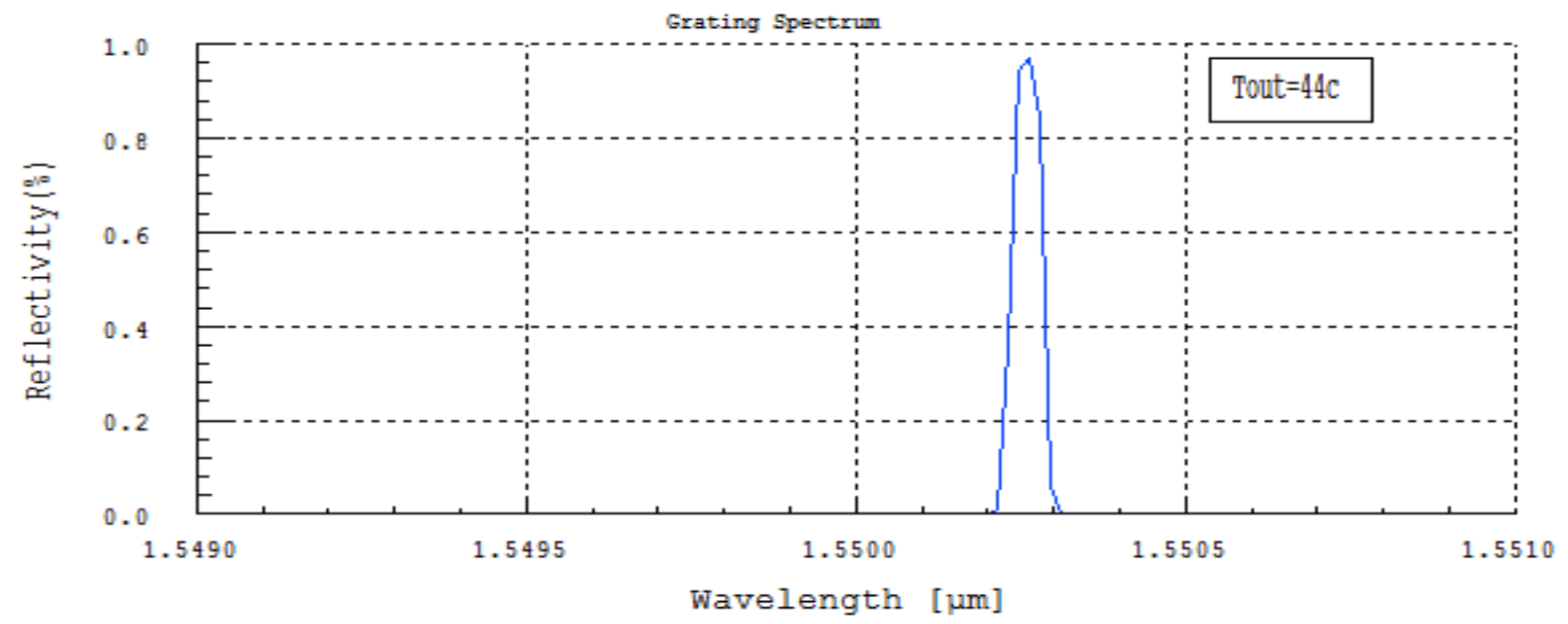

Figure 7. Apodized reflectivity of the silica fiber grating spectrum versus the grating wavelength for external temperature of $44{ }^{\circ} \mathrm{C}$ 


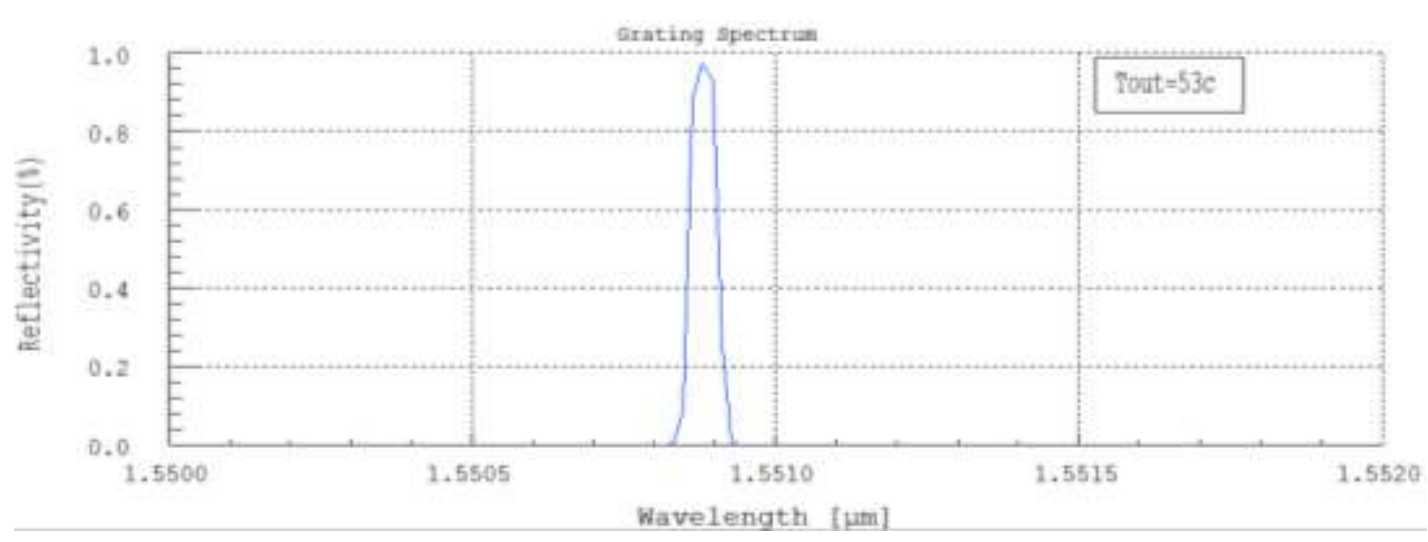

Figure 8. Apodized reflectivity of the Sapphire fiber grating spectrum versus the grating wavelength for external temperature of $53{ }^{\circ} \mathrm{C}$

In case of high temperature variations, we have demonstrated the Bragg wavelength shift induced by higher temperature change for both silica and sapphire fiber Bragg grating as outlined and reported in Figure 9, Figure 10, Figure 11, Figure 12 and Figure 13.

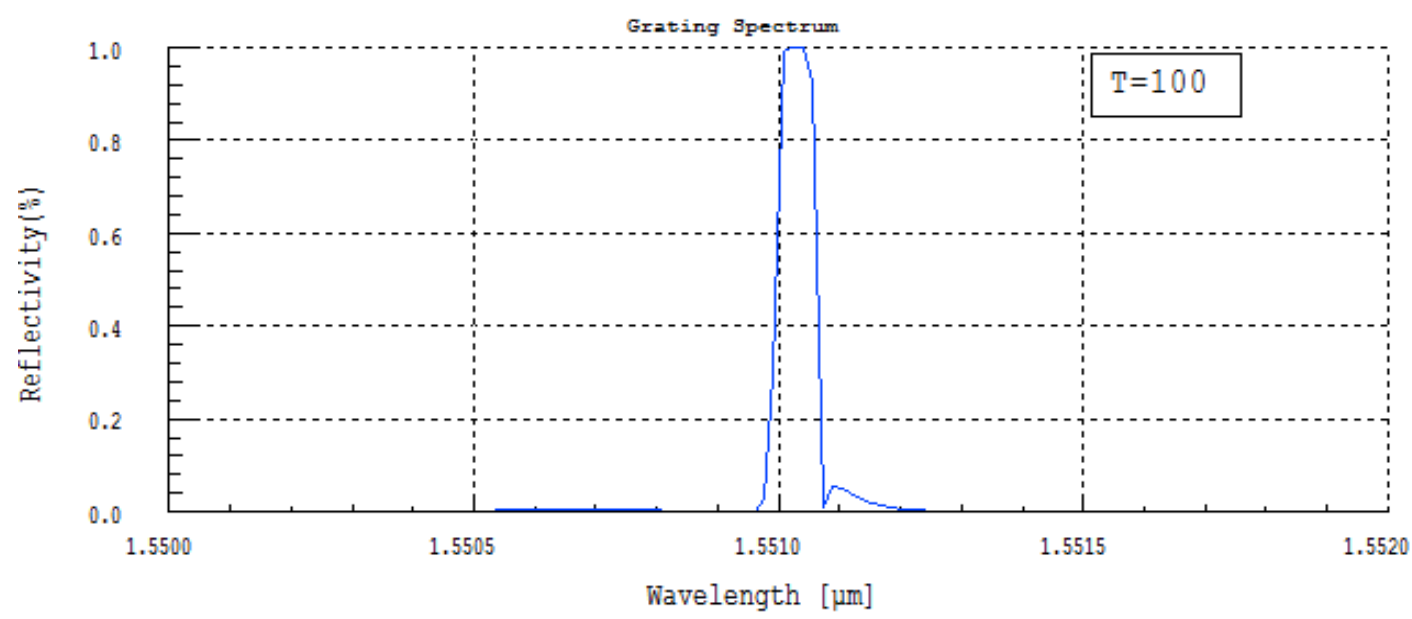

Figure 9. Reflectivity of the silica fiber grating spectrum versus the grating wavelength for high temperature value of 100 ${ }^{\circ} \mathrm{C}$

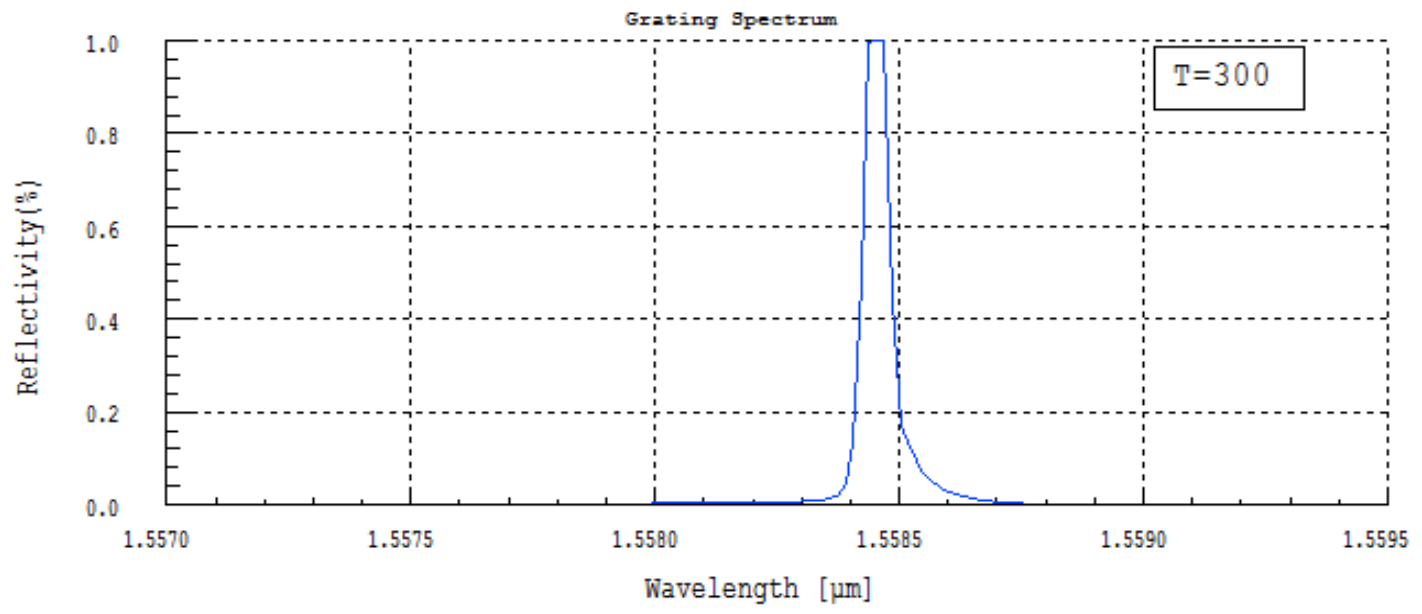

Figure 10. Reflectivity of the Sapphire fiber grating spectrum versus the grating wavelength for high temperature value of $300{ }^{\circ} \mathrm{C}$

High sensitivity sapphire FBG temperature sensors for the signal processing of ... (Mahmoud M. A. Eid) 


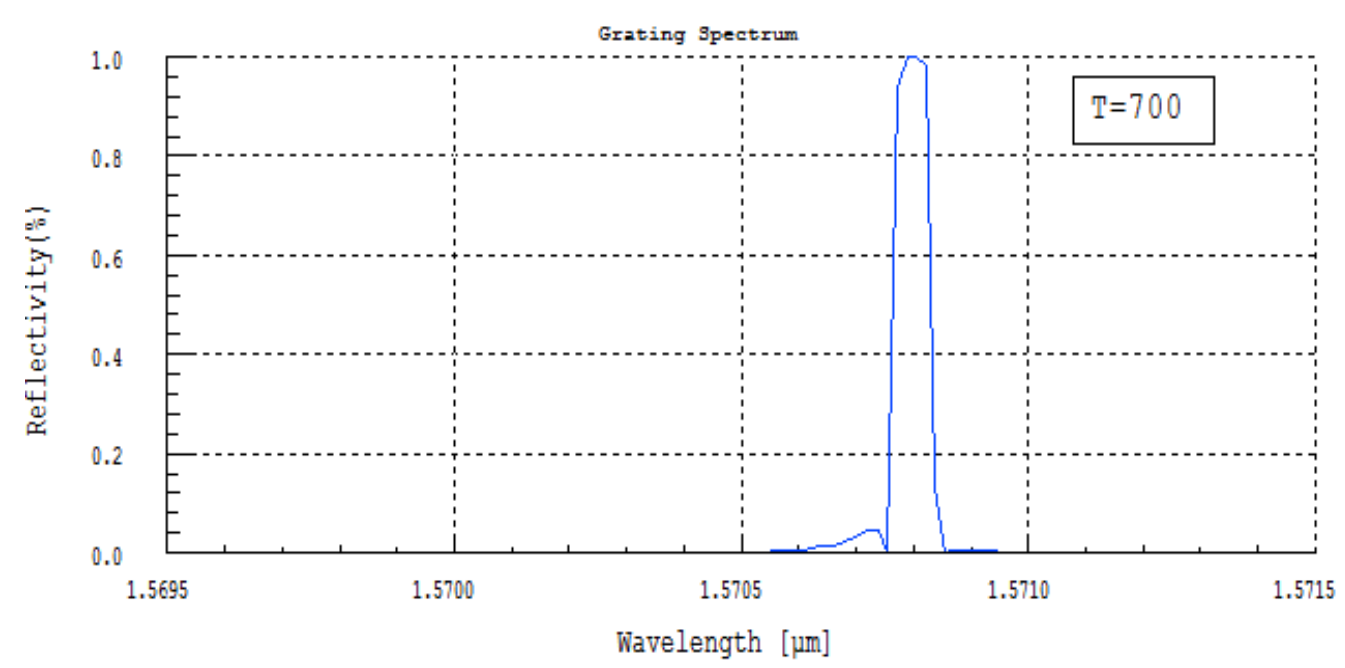

Figure 11. Reflectivity of the Sapphire fiber grating spectrum versus the grating wavelength for high temperature value of $700{ }^{\circ} \mathrm{C}$

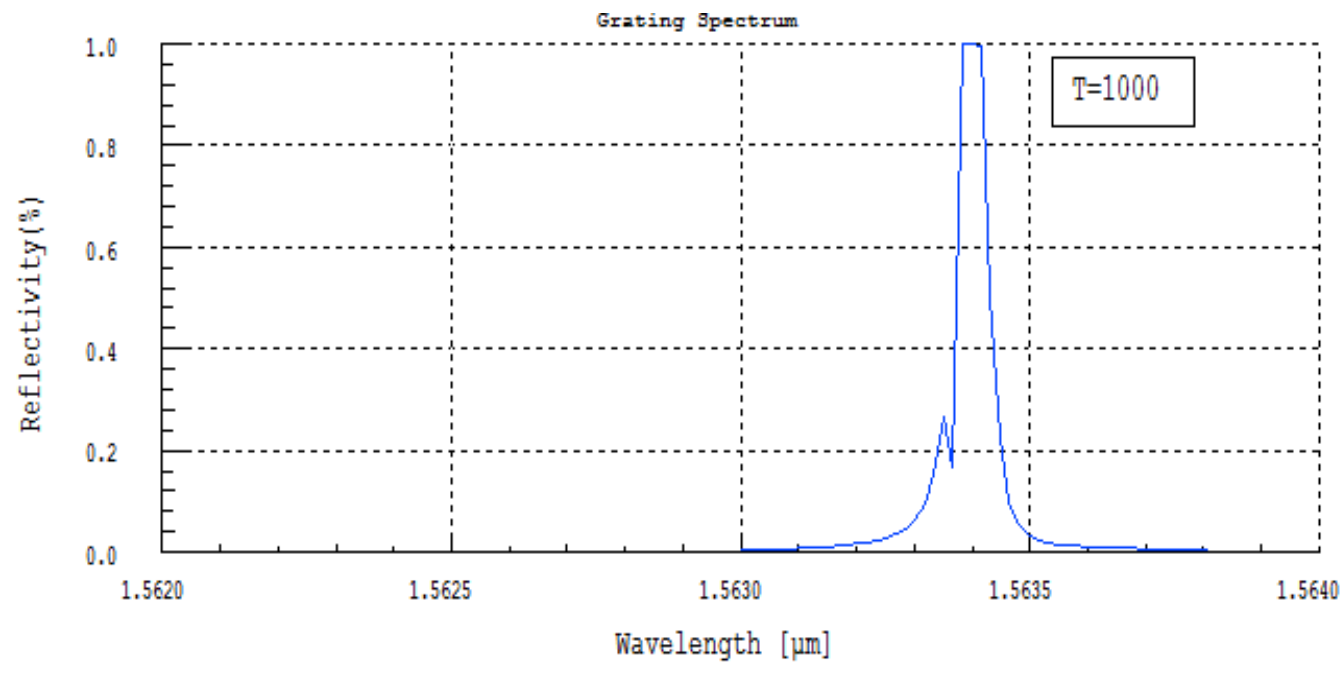

Figure 12. Reflectivity of the silica fiber grating spectrum versus the grating wavelength for high temperature value of $1000{ }^{\circ} \mathrm{C}$

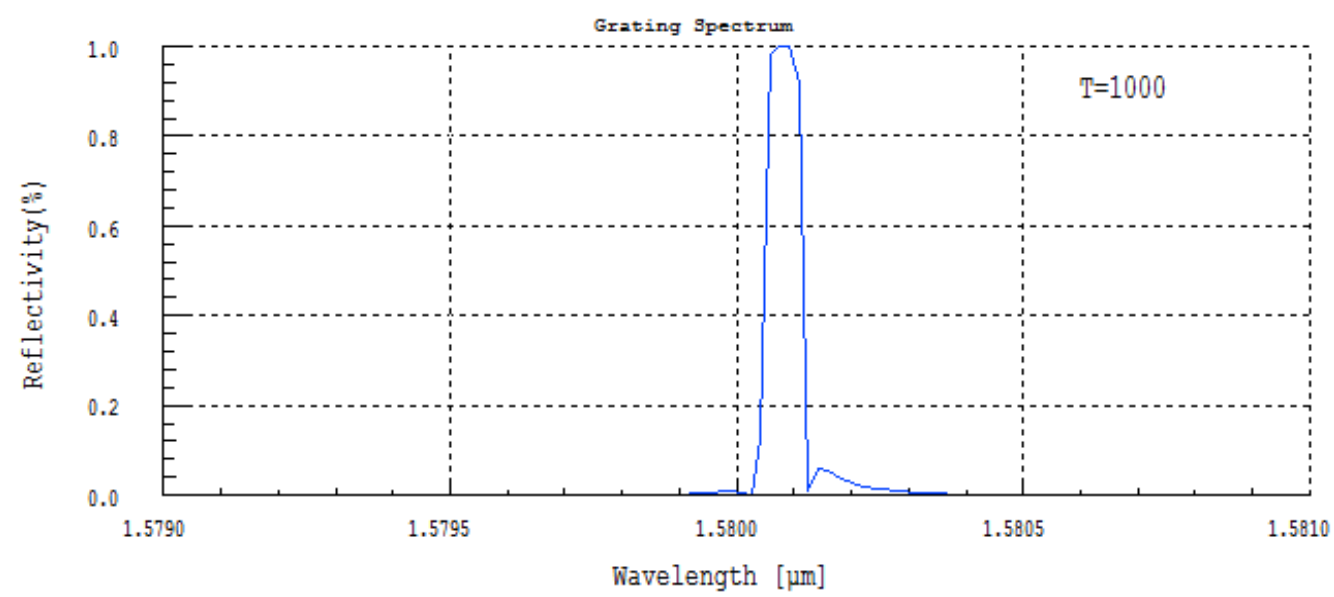

Figure 13. Reflectivity of the Sapphire fiber grating spectrum versus the grating wavelength for high temperature value of $1000{ }^{\circ} \mathrm{C}$ 


\section{CONCLUSION}

We have simulated the high sensitivity sapphire FBG temperature sensors for the signal processing of the data communications technology. It is reported that temperature sensitivity of sapphire FBG nearly $0.11 \mathrm{pm} /{ }^{\circ} \mathrm{C}$, where its value is three times higher than silica FBG due to high sapphire index factor. Two FBG sensors were tested up to $1000{ }^{\circ} \mathrm{C}$ by using a Gaussian apodization type, side lobes in reflectivity spectrum are totally suppressed.

\section{REFERENCES}

[1] J. Paul Bednar, "An all-optical pressure sensor for nuclear power plant applications", M.Sc. Thesis, The Pennsylvania State University, May 2012.

[2] A. Fernandez, et al., "Temperature monitoring of nuclear reactor cores with multiplexed fiber Bragg grating sensors," Optical Engineering, vol. 41, no. 6, pp. 1246-1254, Jun. 2002.

[3] A. Gusarov, et al., "Effect of gamma neutron nuclear reactor radiation on the properties of bragg gratings written in photosensitive ge-doped optical fibre," Nuclear Instruments and Methods in physics Research B, vol. 187, no. 1, pp.79-86, 2002.

[4] G. Cheymol, et al., "High level gamma and neutron irradiation of silica optical fibers in CEA OSIRIS nuclear reactor," IEEE Trans. Nucl. Sci., vol. 55, no. 4, pp. 2252-2258, Aug. 2008.

[5] A. Gusarov and S. K. Hoeffgen, "Radiation effects on fiber gratings," IEEE Transactions on Nuclear Science, vol. 60, no. 3, pp. 2037-2053, 2013.

[6] A. Fernandez, et al., "Radiation-resistant WDM optical link for thermonuclear fusion reactor instrumentation," IEEE Transactions on Nuclear Science, vol. 48, no. 5, pp.1708-1712, Oct. 2001.

[7] Sunita P. Ugale, V. Mishra,"Modeling and characterization of fiber Bragg grating for maximum reflectivity," Optik, vol. 122, no. 22, pp. 1990-1993, 2011.

[8] Ahmed Nabih Zaki Rashed, et al., "Optimum Flat gain with optical amplification technique based on both gain flattening filters and fiber bragg grating methods," Journal of Nanoelectronics and Optoelectronics, vol. 13, no. 5, pp. 665-676, May 2018.

[9] K.-C. Lin, et al.," Effects of gamma radiation on optical fibre sensors," IEE Proc.-Optoelectron., vol. 151, no. 1, pp. 12-15, Feb. 2004.

[10] G. Yang, et al., "Effect of gamma radiation on the reflectance spectrum of fiber Bragg gratings," Optik, vol. 124, no. 15, pp. 2246-2250, 2013.

[11] Ahmed Nabih Zaki Rashed, "Harmful effects of gamma irradiation on optical Fiber communication system links under thermal environment effects," International Journal on Electronics and Communication Technology, vol. 3, no.1, pp. 71-75, 2012.

[12] Ahmed Nabih Zaki Rashed, et al.,"The trade off between different modulation schemes for maximum long reach high data transmission capacity optical orthogonal frequency division multiplexing (OOFDM)," Wireless Personal Communications Journal, Springer Publisher, vol. 101, no. 1, pp. 325-337, 2018, doi: 10.1007/s11277-018-5690-9.

[13] A. Bhardwaj, G. Soni," Performance analysis of optical communication system using fiber bragg grating," SSRG Int. J. Electron. Commun. Eng. (SSRG-IJECE), vol. 2, no.1, pp. 160-166, Jan. 2015.

[14] R. Karthikeyan, et al.," OFDM Signal Improvement Using Radio over Fiber for Wireless System," IRACST International Journal of Computer Networks and Wireless Communications (IJCNWC), vol. 3, no. 3, pp. 22503501, Jun. 2013.

[15] P. Biswas, et al., "Investigation on packages of fiber Bragg grating for use as embeddable strain sensor in concrete structure," Sensors and Actuators, vol. 157, no. 1, pp. 77-83, 2010.

[16] D. Sporea, A. Sporea, "Radiation effects in sapphire optical fibers," Phys. Stat. vol. 4, no. 3, pp.1356- 1359, 2007.

[17] G. J. de Villiers, et al.,"In-core high temperature measurement using fiber-Bragg gratings for nuclear reactors," Applied Thermal Engineering, vol. 38, pp.143-150,2012.

[18] D. Grobnic, et al., "Sapphire fibre Bragg grating sensor made using Femtosecond laser radiation for ultrahigh temperature applications," IEEE Photonics Technology Letters, vol. 16, no. 11, pp. 2505-2507, Nov. 2004.

[19] IS Amiri, et al., "Mathematical model analysis of dispersion and loss in photonic crystal fibers," Journal of Optical Communications, Apr. 2019, doi: 10.1515/joc-2019-0052.

[20] IS Amiri, et al., "Basic functions of fiber bragg grating effects on the optical fiber systems performance efficiency," Journal of Optical Communications, Apr. 2019, doi: 10.1515/joc-2019-0042.

[21] P. Ferdinand, et al 'Optical fibre Bragg grating sensors for structure monitoring within the nuclear power plants," Optical Fibre Sensing and Systems in Nuclear Environments, pp.11-20 ,1994.

[22] IS Amiri, et al., "Optical networks performance optimization based on hybrid configurations of optical fiber amplifiers and optical receivers," Journal of Optical Communications, Jul. 2019, doi: https://doi.org/10.1515/joc2019-0153.

[23] João L. Rebola and Adolfo V. T. Cartaxo., "Performance optimization of Gaussian apodized fiber Bragg grating filters in WDM systems," Journal of Lightwave Technology., vol. 20, no. 8, pp. 1537-1544, 2002.

[24] N.-H. Sun, et al., "Numerical analysis of apodized fiber Bragg gratings using coupled mode theory," Progress in Electromagnetics Research, vol. 99, pp. 289-306,2009.

[25] Ahmed Nabih Zaki Rashed, et al., "Transmission performance simulation study evaluation for high speed radio over fiber communication systems," Wireless Personal Communications Journal, vol. 103, no. 2, pp. 1765-1779, Nov. 2018, doi: 10.1007/s11277-018-5879-y. 
[26] Ahmed Nabih Zaki Rashed, Mohammed Salah F. Tabbour "Best candidate integrated technology for low noise, high speed, and wide bandwidth based transimpedance amplifiers in optical computing systems and optical fiber applications," International Journal of Communication Systems, vol. 31, no. 17, paper id: e3801, Nov. 2018, doi: 10.1002/dac.3801.

[27] Ahmed Nabih Zaki Rashed, et al., "20 Gb/s Hybrid CWDM/DWDM for Extended Reach Fiber to the Home Network Applications," Proc. Natl. Acad. Sci., India, Sect. A Phys. Sci, vol. 89, no. 4, pp. 653-662, Oct.-Dec. 2019, doi: 10.1007/s40010-018-0526-2.

[28] Ahmed Nabih Zaki Rashed, et al., "Design of human blood sensor using symmetric dual core photonic crystal fiber," Results in Physics, vol. 11, pp. 964-965, Dec. 2018.

[29] S. Praveen Chakkravarthy, et al., "Ultra high transmission capacity based on optical first order soliton propagation systems," Results in Physics, vol. 12, pp. 512-513, Mar. 2019.

[30] Ahmed Nabih Zaki Rashed, et al., "Transmittivity/reflectivity, bandwidth, and ripple factor level measurement for different refractive index fiber grating shape profiles," Journal of Optical Communications, Feb. 2019, doi: 10.1515/joc-2018-0233.

[31] T.V. Ramana, et al., "Numerical analysis of circularly polarized modes in coreless photonic crystal fiber," Results in Physics (Elsevier), vol. 13, Article 102140, Jun. 2019, doi: 10.1016/j.rinp.2019.02.076.

[32] Ahmed Nabih Zaki Rashed, et al., "The switching of optoelectronics to full optical computing operations based on nonlinear metamaterials," Results in Physics, vol. 13, Article 102152, Jun. 2019, doi: 10.1016/j.rinp.2019.02.088.

[33] Ahmed Nabih Zaki Rashed, et al., "Performance enhancement of overall LEO/MEO intersatellite optical wireless communication systems," International Journal of Satellite Communications and Networking, vol. 38, no. 1, pp. 31-40, Jan./Feb. 2020, doi: 10.1002/sat.1306.

[34] IS Amiri, et al., "Spatial continuous wave laser and spatiotemporal VCSEL for high-speed long haul optical wireless communication channels," Journal of Optical Communications, Apr. 2019, doi: 10.1515/joc-2019-0061.

[35] IS Amiri, et al., "Average power model of optical raman amplifiers based on frequency spacing and amplifier section stage optimization," Journal of Optical Communications, May 2019, doi: 10.1515/joc-2019-0081.

[36] Ahmed Nabih Zaki Rashed, et al., "Temperature effects on characteristics and performance of near-infrared wide bandwidth for different avalanche photodiodes structures," Results in Physics, vol. 14, Article 102399, Sep. 2019, doi: 10.1016/j.rinp.2019.102399.

[37] Ahmed Nabih Zaki Rashed, et al., "The effect of using different materials on erbium-doped fiber amplifiers for indoor applications," Results in Physics, vol. 15, paper id: 102650, Dec. 2019, doi: 10.1016/j.rinp.2019.102650.

[38] IS Amiri, et al., "Optical communication transmission systems improvement based on chromatic and polarization mode dispersion compensation simulation management," Optik Journal, vol. 207, article163853, Apr. 2020, doi: 10.1016/j.ijleo.2019.163853.

[39] Hazem M. El-Hageen, et al., "High-speed signal processing and wide band optical semiconductor amplifier in the optical communication systems," Journal of Optical Communications, Aug. 2020, doi: 10.1515/joc-2020-0070.

[40] Aadel M. Alatwi, et al., "Beam divergence and operating wavelength bands effects on free space optics communication channels in local access networks," Journal of Optical Communications, Aug. 2020, doi: 10.1515/joc-2019-0276.

[41] Hazem M. El-Hageen, et al., "Laser measured rate equations with various transmission coders for optimum of data transmission error rates," Indonesian Journal of Electrical Engineering and Computer Science, vol. 20, no. 3, pp. 1406-1412, Dec. 2020, doi: 10.11591/ijeecs.v20.i3.pp1406-1412.

[42] Mahmoud M. A. Eid, et al., "Highly sensitive nonlinear photonic crystal fiber based sensor for chemical sensing applications," Microsystem Technologies Journal, Sep. 2020, doi: 10.1007/s00542-020-05019-w.

[43] Mahmoud M. A. Eid, et al., "Fabry Perot laser properties with high pump lasers for upgrading fiber optic transceiver systems," Journal of Optical Communications, Sep. 2020, doi: 10.1515/joc-2020-0146.

[44] Mahmoud M. A. Eid, et al., "Spatial optical transceiver system-based key solution for high data rates in measured index multimode optical fibers for indoor applications," Journal of Optical Communications, Sep. 2020, doi: 10.1515/joc-2020-0117.

[45] Mahmoud M. A. Eid, et al., "Simulation study of signal gain optimization based on hybrid composition techniques for high speed optically dense multiplexed systems," Journal of Optical Communications, Sep. 2020, doi: 10.1515/joc-2020-0150.

[46] Aadel M. Alatwi, Ahmed Nabih Zaki Rashed, "Hybrid CPFSK/OQPSK modulation transmission techniques' performance efficiency with RZ line coding-based fiber systems in passive optical networks," Indonesian Journal of Electrical Engineering and Computer Science, vol. 21, no. 1, pp. 263-270, January 2021, doi: 10.11591/ijeecs.v21.i1.pp263-270.

[47] Aadel M. Alatwi, Ahmed Nabih Zaki Rashed, "An analytical method with numerical results to be used in the design of optical slab waveguides for optical communication system applications," Indonesian Journal of Electrical Engineering and Computer Science, vol. 21, no. 1, pp. 278-286, Jan 2021, doi: 10.11591/ijeecs.v21.i1.pp278-286.

[48] Aadel M. Alatwi, Ahmed Nabih Zaki Rashed, "Conventional doped silica/fluoride glass fibers for low loss and minimum dispersion effects," Indonesian Journal of Electrical Engineering and Computer Science, vol. 21, no. 1, pp. 287-295, Jan 2021, doi: 10.11591/ijeecs.v21.i1.pp287-295.

[49] Hazem M. El-Hageen, et al., "Spatial optical transmitter based on on/off keying line coding modulation scheme for optimum performance of telecommunication systems," Indonesian Journal of Electrical Engineering and Computer Science, vol. 21, no. 1, pp. 305-312, Jan 2021, doi: 10.11591/ijeecs.v21.i1.pp305-312. 